\title{
Discriminating permanent from temporary rivers with traits of chironomid genera
}

\author{
Sónia R. Q. Serra ${ }^{1 *}$, Manuel A. S. Graça ${ }^{1}$, Sylvain Dolédec ${ }^{2}$ and Maria João Feio ${ }^{1}$ \\ 1 Department of Life Sciences, MARE - Marine and Environmental Sciences Centre, University of Coimbra, Largo Marquês de \\ Pombal, 3004-517 Coimbra, Portugal \\ 2 University Lyon 1, UMR 5023 LEHNA, Biodiversité des Ecosystèmes Lotiques, Bât Forel, 69622 Villeurbanne Cedex, France
}

Received 18 July 2016; Accepted 06 February 2017

\begin{abstract}
Chironomidae are diverse and present a wide variety of ecological preferences. Thus, they have high potential in establishing reference conditions for river bioassessment and in providing functional information, especially when other macroinvertebrates are poorly represented. However, because of taxonomic difficulties and poor knowledge of traits, they are neglected in bioassessment programmes and kept at coarser taxonomic levels, reducing the discrimination power of invertebrate-based diagnostic tools. Here, we compared the efficiency of Chironomidae at the subfamily and genus levels and their biological traits (Eltonian and morphological) in the distinction between permanent (medium altitude and lowland) and temporary Mediterranean streams. We established a priori predictions on the expected Chironomidae trait categories in each stream type, conferring the best adaptations to particular environmental constraints. Genus composition (not subfamily) and respective trait categories differed among the three stream types. Both biological traits identified differences between stream types. Among Eltonian traits, diapause stages segregated permanent medium altitude from lowland and temporary stream assemblages, reflecting adaptations to temperature and flow regime variations. Substrate relation and size distinguished temporary from permanent stream assemblages, interpreted as an adaptation to unstable sediments and irregular flow regimes. Morphological traits associated with mobility and foraging (e.g., body setae, Lauterborn sensory organs) discriminated temporary from permanent stream assemblages, reflecting differences in temporal and spatial stream heterogeneity. The use of these morphological characteristics relying on the observation of few characteristics, offers an alternative to the use of Chironomidae Eltonian traits in bioassessment and ecological studies, without a need for high taxonomic expertise.
\end{abstract}

Key words: Diptera / traits / flow regime / bioassessment / reference conditions

\section{Introduction}

Climate, geomorphology and hydrological regime influence water quality, quantity of food resources, dominant substrate, temperature and dissolved oxygen available in space and time. As a result, stream and river habitats will naturally support a particular diversity of benthic macroinvertebrate communities, with specific structure and functions (Poff, 1996; Heino et al., 2007). Evaluating their biological and ecological integrity requires accounting for this natural variance, based on the Reference Condition Approach (Reynoldson et al., 1997). For this reason, grouping rivers and streams with similar environmental and biological characteristics into river

\footnotetext{
*Corresponding author: sonia.rqs@gmail.com
}

types is the basis of ecological monitoring programmes in Europe (Water Framework Directive, European Commission, 2000).

Headwater temperate streams, with well-oxygenated waters and diverse habitats usually support high macroinvertebrate diversity, including Ephemeroptera, Plecoptera and Trichoptera (EPT), which are widely used bioindicators (Karr, 1991; Rosenberg and Resh, 1993). In contrast, rhithral habitats are usually restricted to temperate lowland streams, resulting in communities that are naturally poor in EPT (Allan, 1995; Hawkins and Norris, 2000; Harrison et al., 2004), which does not necessarily mean poor water quality. Mediterranean rivers exhibit high seasonal discharge variations, resulting frequently in flow intermittence. Macroinvertebrates must have adaptive mechanisms and behaviours to survive drought and floods (desiccation-resistance and dispersal). Here, EPT 
taxa are uncommon while Odonata, Coleoptera and Heteroptera are more frequent (Bonada et al., 2007a).

Independently of the river type, Chironomidae (Diptera) are always present and represent one of the most conspicuous and ecologically diverse invertebrate groups. However, the ubiquity of this family is normally confounded with a high tolerance to pollution and other pressures (e.g., Chironomus spp.; Armitage et al., 1995), while in fact this family includes very sensitive taxa, such as Diamesa spp., Zavrelimyia spp. and Stilocladius montanus (Brown et al., 2007; Lencioni et al., 2012, 2013). Nevertheless, they have been neglected as environmental indicators in running waters because of their difficult identification and have not been considered at higher levels of taxonomic resolution in regular biomonitoring programmes (Wymer and Cook, 2003; Calle-Martínez and Casas, 2006; Móra et al., 2008). For this reason, they are often identified to family or subfamily levels in community ecology or bioassessment studies. Such practices may result in the failure to detect ecological differences, especially in systems naturally low in EPT taxa, but where Chironomidae can be diverse (Wymer and Cook, 2003; Greffard et al., 2011). For example in Mediterranean streams, Chironomidae at the genus or species level have made it possible to distinguish siliceous headwaters, middle altitude streams, and calcareous and temporary streams (Puntí et al., 2007, 2009).

As an alternative and complement to taxonomy-based approaches, multiple-trait-based (MTB) approaches have been increasingly used in the assessment of river and stream integrity (Statzner et al., 2008; Dolédec and Statzner, 2010; Feio and Dolédec, 2012). MTB approaches can not only reveal the cause of impairment but also potentially offer a functional perspective of this impact, unravelling mechanisms structuring stream communities (Usseglio-Polatera et al., 2000; Bady et al., 2005; Devin et al., 2005; Statzner et al., 2005).

Eltonian traits are related to organisms' functional roles and their impact in the ecosystems including life cycle aspects, and physiological and behavioural characteristics (Serra et al., 2016). In addition to biological traits common to all benthic macroinvertebrates, Chironomidae also have morphological-specific traits, such as body setae, type of antennae and Lauterborn organs related to feeding, defence and locomotion. Previous studies with terrestrial organisms have shown a relationship between morphological traits and species in the environment (Makkonen et al., 2011; Astor et al., 2014). Here we evaluate the relevance of Chironomidae genera, Eltonian traits derived from a European trait database (Appendix Table A1 available online), and morphological traits directly observed on sampled specimens (Appendix Table A2 available online) in the segregation of stream types (permanent, medium altitude and lowland; and temporary). We hypothesise that Chironomidae-based taxonomic and trait information at the genus level, without considering other invertebrate groups, will provide (in contrast to the subfamily level) a clear segregation of stream types, due to the high between-genera variety of ecological preferences within this family.

\section{Materials and methods}

\section{Study area, selection of stream types and sites}

The study sites were located in two contrasting climatic areas of the Portuguese territory: a northern area under the influence of the Atlantic-temperate climate and a southern area under the influence of the Mediterranean climate. In the northern Atlantic-temperate climate region, two types of permanent (P) streams were studied: PM, medium-altitude streams; and PL, permanent lowland streams. PM streams were characterised by altitude $<600$ m a.s.l. (mean \pm SD: $343 \pm 223$ m a.s.l.), low mean annual temperature $\left(12-13{ }^{\circ} \mathrm{C}\right)$, relatively high mean annual precipitation $(1193 \pm 352 \mathrm{~mm})$ and siliceous lithology (acidic rocks, igneous nature) (Table 1). The PL type included low-altitude streams $(44 \pm 44 \mathrm{~m}$ a.s.l.), characterised by relatively high mean annual temperatures $\left(15^{\circ} \mathrm{C}\right)$, low annual rainfall $(941 \pm 118 \mathrm{~mm})$ and mixed geology (limestone and siliceous nature) (Table 1). In the Mediterranean climate, seven samples were collected in temporary southern streams (temporary Mediterranean, TM) in the Guadiana River catchment. These streams were located at low altitude ( $183 \pm 75 \mathrm{~m}$ a.s.1.), in an area with high annual temperature $\left(16^{\circ} \mathrm{C}\right)$, a dry summer, and low and irregular winter precipitation $(628 \pm 86 \mathrm{~mm})$ and mixed geology (limestone and siliceous nature) (Table 1). A total of 25 benthic macroinvertebrate samples were collected from the selected stream types during the spring of 2011 and 2012: ten in PM, eight in PL and seven in TM. All sites were considered Least Disturbed (Stoddard et al., 2006; Feio et al., 2014) considering the water quality, hydromorphological conditions and land use.

\section{Sampling collection, processing and mounting}

Benthic macroinvertebrate samples were collected at the study sites with a kick net $(500 \mu \mathrm{m}$ mesh size; $0.25 \mathrm{~m} \times 0.25 \mathrm{~m}$ opening) following a multi-habitat protocol (INAG, 2008). Each sample was fixed with formalin $(4 \%)$. Chironomidae larvae were separated and preserved in ethanol $(70 \%)$. Chironomidae individuals were then divided into morphological types and counted under a stereomicroscope; pre-separation of taxa groups by easily observable morphological features was done to facilitate mounting and identification. Then, larvae were digested in caustic potash $(\mathrm{KOH}, 10 \%)$ at $85^{\circ} \mathrm{C}$ for about 15-20 $\mathrm{min}$, and then washed for $5 \mathrm{~min}$ in distilled water, removing the muscle and soft tissue. Afterwards, they were dehydrated for $3 \mathrm{~min}$ in $70 \%$ ethanol, followed by $3 \mathrm{~min}$ in $96 \%$ ethanol. Finally, heads and bodies were mounted separately in slides with the Euparal medium (according to Andersen et al., 2013) and identified to the lowest 
Table 1. Abiotic variables recorded at each site (mean $\pm \mathrm{SD}$ ) and transformation applied in the principal components analysis.

\begin{tabular}{|c|c|c|c|c|c|}
\hline Variables & Units & Transformation & $\mathrm{PL}$ & $\mathrm{PM}$ & TM \\
\hline Latitude & $\begin{array}{l}\text { WGS- } 84 \text { decimal } \\
\text { coordinates }\end{array}$ & $\log (x+1)$ & $39.957 \pm 0.383$ & $40.252 \pm 0.216$ & $37.535 \pm 0.034$ \\
\hline Altitude & m a.s.1. & $\log (x+1)$ & $44 \pm 44$ & $343 \pm 223$ & $183 \pm 75$ \\
\hline Conductivity & $\mu \mathrm{S} . \mathrm{cm}^{-1}$ & $\log (x+1)$ & $404.34 \pm 228.67$ & $79.25 \pm 60.91$ & $424.71 \pm 223.53$ \\
\hline Mean annual precipitation ${ }^{\mathrm{a}}$ & $\mathrm{mm}$ & $\log (x+1)$ & $941 \pm 118$ & $1193 \pm 352$ & $628 \pm 86$ \\
\hline Mean annual temperature ${ }^{a}$ & ${ }^{\circ} \mathrm{C}$ & $\log (x+1)$ & 15 & $12-13$ & 16 \\
\hline Drainage area & $\mathrm{km}^{2}$ & $\log (x+1)$ & $110.14 \pm 194.68$ & $113.59 \pm 139.52$ & $118.42 \pm 91.77$ \\
\hline Lithology (categorical) ${ }^{\mathrm{a}}$ & $\begin{array}{l}\text { Sedimentary (1) } \\
\text { Sedimentary } \\
\text { + Metamorphic (2) }\end{array}$ & Square root & $\begin{array}{l}\text { Sedimentary } \\
\quad+\text { Metamorphic }\end{array}$ & $\begin{array}{l}\text { Sedimentary } \\
\quad+\text { Metamorphic }\end{array}$ & Sedimentary \\
\hline
\end{tabular}

a Data from the Portuguese Environmental Agency (2007) Available at http://sniamb.apambiente.pt/Home/Default.htm

possible taxonomic level under a microscope $(400-1000 \times$ magnification), according to the guides for Palearctic/ Holarctic Chironomidae taxa (e.g., Cranston, 1982; Lencioni et al., 2007; Andersen et al., 2013). The collection of Chironomidae from Mediterranean rivers and an existing preliminary key from Prat and Rieradevall supported the identification (Prat and Rieradevall, 2014).

\section{Trait composition}

Morphological traits were analysed in an exploratory way, since functional morphology of Chironomidae is still mostly unfamiliar. Each identified genus was characterised according to its observed morphological traits. General larval morphology, which is important in the distinction of each morphological trait, is shown in Appendix Figure A1 available online. The morphological traits selected were those related to the potential functional role of Chironomidae in the ecosystem: structures such as the mentum, premandibles, antennae and Lauterborn organs that articulate with the head capsule (Appendix Fig. A1(A), (B) and (E-H) available online), involved in feeding and stimuli perception (Cranston, 1995); body setae, claws of parapods and procercus (Appendix Fig. A1(B-D) available online), related with locomotion, substrate relation and feeding behaviour of individuals (Coffman and Ferrington, 1996); and anal tubules related to active salt absorption (Cranston, 1995).

Eltonian trait information was based on the Serra et al. (2016) trait database. For both types of traits, the affinity of a taxon to a given trait category was quantified following Franquet (1996): the higher the number of references in the European literature associating a taxon to a trait category, the greater its affinity. Affinity scores given trait categories were: 0 - no affinity, 1 - low, 2 - medium and 3 - high affinities. Within each trait (Eltonian or morphological), trait categories were standardised to sum 1, following the fuzzy coding procedure (Chevenet et al., 1994), ensuring that all taxa have the same weight in further analyses. Traits without information in all their categories for more than $50 \%$ of Chironomidae taxa present in samples were not used in further analyses (marked in Appendix Table A1 available online available online). The trait profiles of site assemblages were obtained by computing the cross-product between taxon abundances [transformed in $\log (x+1)$ ] and standardised trait categories. This cross product was then rescaled by trait to obtain the proportion of individuals that have a given trait category in a given site. This resulted in a relative trait abundance matrix that allowed us to compare the trait composition of sites across stream types.

Eltonian and morphological traits were handled separately considering their different origin: the first was derived from a European database whereas the second resulted from the observation of morphological attributes of Chironomids from samples.

\section{Data analyses}

A principal component analysis (PCA) was performed on environmental variables after their transformation for normality (Table 1) to confirm the differences between stream types. In addition, permutational univariate analysis of variance (PERMANOVA using 999 permutations) was used to test for the statistical significance of the differences (PM, PL and TM) (PRIMER 6+ PERMANOVA package).

For Chironomidae composition, non-metric multidimensional scaling analysis (NMDS) was used (log $[x+1]$ transformation; Bray-Curtis similarity coefficient) to depict differences among stream types (PM, PL and TM). Similarly to above, the statistical significance of differences was determined with a PERMANOVA (999 permutations). NMDS and PERMANOVA were executed considering two different levels of taxonomic resolution: subfamily and genus. To assess the dominating Chironomidae genera in each stream type, we used a similarity percentage of species analysis (SIMPER; cut-off cumulative percentage of $90 \%$; PRIMER $6+$ PERMANOVA package).

To investigate taxon redundancy among Eltonian or morphological traits and within traits (between traitcategories), we performed a centred PCA on each trait separately (FPCA). We measured the correlation between two traits using the $R v$-coefficient, which is a 
multidimensional equivalent of the ordinary correlation coefficient between two variables (Robert and Escoufier, 1976). Only the trait explaining more variability was retained for further analysis, from the highly correlated traits $(\geq 0.85)$.

The trait-by-site matrix was analysed using a fuzzy correspondence analysis (FCA) enabling the joint ordination of sites and trait categories (Chevenet et al., 1994). The variance explained by a trait for separating sites is known as the correlation ratio (i.e., the higher the correlation ratio, the higher the separation of sites across trait categories). The trait separation across stream types was assessed through a between-class analysis (BCA-FCA, class: stream type; Dolédec and Chessel, 1987; Ter Braak, 1988; Chessel et al., 2004). We tested the significance of the trait composition variance across stream types against simulated values obtained after 999 permutations of the rows of the trait-composition array. Trait categories' individual differences of traits that contributed more to the differentiation among stream types in the BCA-FCA were assessed using a KruskalWallis test. Trait categories showing significant differences among types were subsequently tested using Dunn's test of multiple comparisons to ascertain between which streams types significant differences occur.

Trait composition was analysed using the ade4 library (Thioulouse et al., 1997; Chessel et al., 2004; Dray and Dufour, 2007; Dray et al., 2007) in R freeware (R Core Team, 2015).

\section{Results}

\section{Environmental conditions}

PM, PL and TM streams were segregated by the PCA (Fig. 1) based on their environmental characteristics. The first two axes explained $74 \%$ of the total variance $(\mathrm{PC} 1=48 \% ; \mathrm{PC} 2=26 \%)$. Differences between stream type groups were statistically significant (PERMANOVA: Pseudo- $F=18.558, P<0.001$ ).

\section{Taxonomic composition}

From the samples collected for this study $\sim 8.5$ thousand Chironomidae individuals were studied. The three stream types differed according to Chironomidae composition (pairwise tests in Table 2). Considering the abundance of Chironomidae taxa identified at the subfamily level, significant differences occurred between stream types (Fig. 2(A); PERMANOVA: pseudo- $F$ global test $=3.466, P=0.004)$. Pairwise tests showed significant differences between temporary (TM) and permanent streams (PL and PM), but not within permanent streams (Table 2). However, at the genus level, the segregation between all types was statistically significant (PERMANOVA: pseudo- $F$ global test $=2.962, P=0.001$; Fig. 2(B); Table 2).

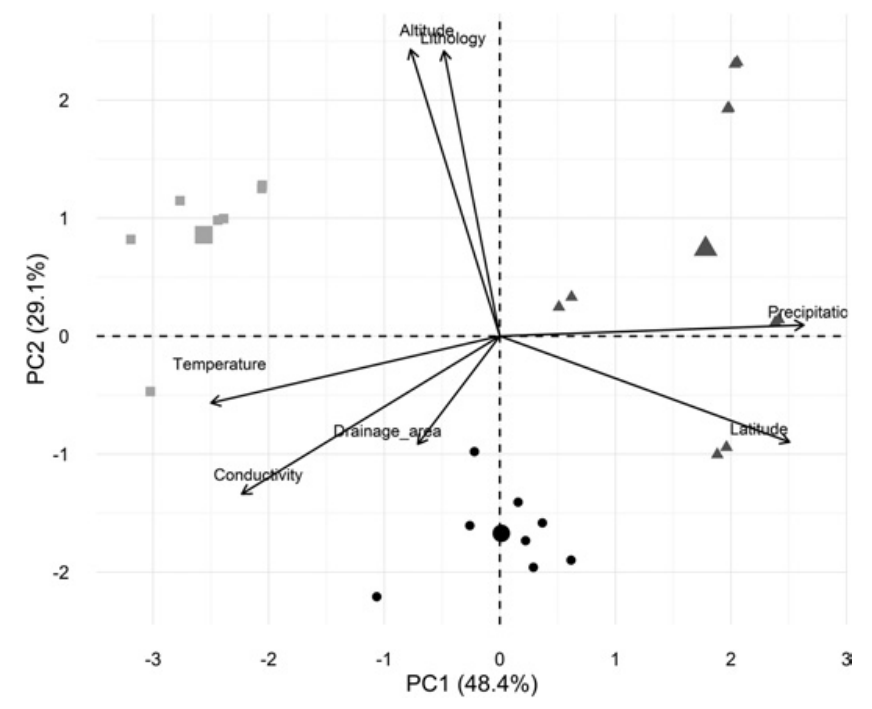

Fig. 1. Principal component analysis of the study sites attending to their abiotic characterisation. The stream types are identified as: black circles - permanent lowland streams, PL; dark grey triangles - permanent medium-altitude streams, PM; light grey squares - temporary southern streams, TM (more information in Table 1). The larger symbols (circle, triangle and square) represent the centroids of each corresponding stream type (PL, PM and TM, respectively).

Taking into account the most contributive taxa of each stream type (cumulative contribution up to $90 \%$ to within stream type similarity), six taxa were common to permanent streams PM and PL, while only three were common to PM and TM or PL and TM (Table 3). The genus Tvetenia (Orthocladiinae) was the only taxon common to the three lists (Table 3). In PM streams, Conchapelopia sp. (Tanypodinae) had the highest contribution to similarity (38\%) followed by Rheotanytarsus sp. (Tanytarsini; 13\%), Parametriocnemus sp. (Orthocladiinae; 10\%) and Polypedilum sp. (Chironomini; 8\%). Therefore, Tanypodinae was the representative subfamily of this stream type (38\%). In PL streams, the most representative genera were Parametriocnemus sp. (Orthocladiinae; 23\%) and Polypedilum sp. (Chironomini; 15\%), followed by Tvetenia sp. (Orthocladiinae, 9\%). Prodiamesa olivacea was the only Prodiamesinae selected as an important contributor and was exclusive to lowland streams; however, Orthocladiinae was the most contributive subfamily of this stream type (46\%). In temporary streams (TMs) the most contributive taxa were Potthastia gr. gaedii (Diamesinae; 16\%) and Orthocladiinae specimens from the undistinguished group of CricotopusOrthocladius-Paratrichocladius (OCP; 15\%), followed by Cladotanytarsus sp. (Tanytarsini) and Ablabesmyia longistyla (Tanypodinae). Overall, Orthocladiinae was the most contributive subfamily for within temporary stream similarity ( $37 \%$; including Corynoneura sp. which was only found in this type of stream).

In our samples, we collected six genera not mentioned in Fauna Europaea (Saether and Spies, 2013) for mainland Portugal: three Orthocladiinae, Paracladius sp., 
Table 2. PERMANOVA pairwise test results on differences between stream types (PL, permanent lowland; PM permanent mediumaltitude; TM, temporary Mediterranean) at subfamily and genus levels.

\begin{tabular}{|c|c|c|c|c|c|c|}
\hline \multirow{2}{*}{ Groups } & \multicolumn{3}{|c|}{ Subfamily } & \multicolumn{3}{|c|}{ Genus } \\
\hline & $t$ & Simul- $p$ & perms & $t$ & Simul- $p$ & perms \\
\hline$\overline{\mathrm{TM}} \neq \mathrm{PM}$ & 1.932 & 0.023 & 966 & 2.097 & 0.001 & 970 \\
\hline $\mathrm{TM} \neq \mathrm{PL}$ & 2.025 & 0.017 & 933 & 1.629 & 0.001 & 935 \\
\hline $\mathrm{PM} \neq \mathrm{PL}$ & 1.604 & 0.085 & 992 & 1.352 & 0.028 & 985 \\
\hline
\end{tabular}
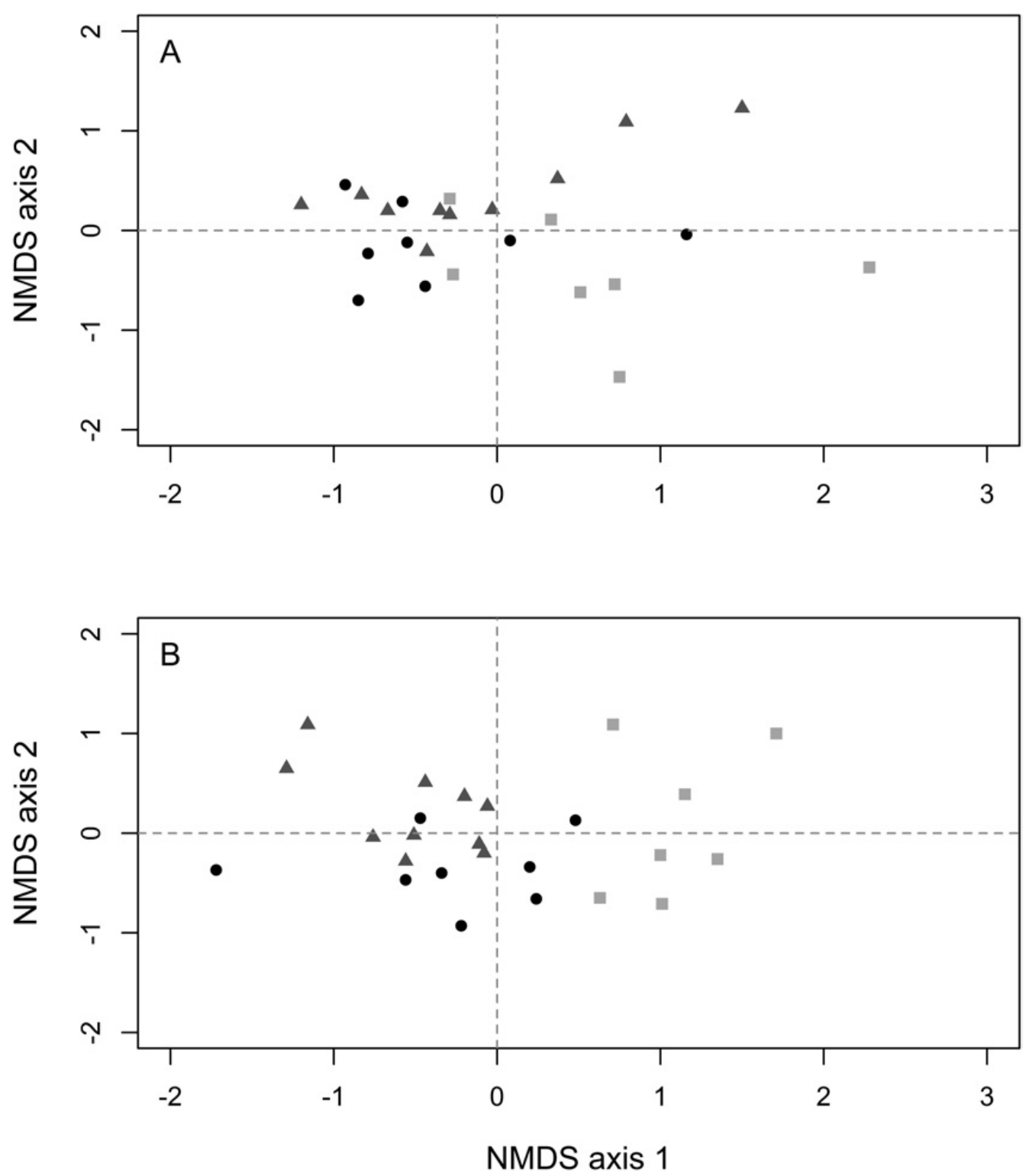

Fig. 2. Non-metric multidimensional scaling analyses based on Chironomidae composition (Bray-Curtis similarity; log-abundance) at: (A) subfamily level; (B) genus level. The stream types are identified as: black circles - permanent lowland streams, PL; dark grey triangles - permanent medium-altitude streams, PM; light grey squares - temporary southern streams, TM.

Epoicocladius sp. and Hydrobaenus sp. found in PL, PM and TM streams, respectively; two Chironomini, Paratendipes sp. found in PL and TM streams and Tribelos sp. found in TM streams; and the Prodiamesinae Odontomesa sp. only collected in some PL streams.

\section{Trait-by-taxa arrays}

From an initial list of 17 Eltonian traits, 12 remained after removing the correlated traits and those with a low amount of information (indicated in Appendix 
Table 3. Percentage of the most contributive taxa, generated by a SIMPER analysis for each group of stream types: PL, permanent lowland; PM, permanent medium-altitude; TM, temporary Mediterranean) considering Chironomidae abundance $(\log (x+1)$ transformation; the cut-off level for cumulative contributions up to $90 \%$ ).

\begin{tabular}{lrrr}
\hline Taxa & PL $(\%)$ & PM $(\%)$ & TM $(\%)$ \\
\hline Tvetenia sp. & 10.5 & 5.6 & 8.8 \\
Conchapelopia sp. & 5.3 & 37.6 & \\
Parametriocnemus sp. & 22.5 & 10.3 & \\
Rheotanytarsus sp. & 5.5 & 13.5 & \\
Polypedilum sp. & 15.0 & 8.3 & \\
Brillia bifida & 4.5 & 4.0 & \\
OCP Orthocladiinae & & 3.2 & 15.0 \\
Tanytarsus sp. & & 2.5 & 3.9 \\
Rheocricotopus chalybeatus & 2.6 & & 4.7 \\
Cladotanytarsus sp. & 2.5 & & 14.6 \\
Potthastia gr. gaedii & & & 15.9 \\
Ablabesmyia longistyla & & & 11.1 \\
Corynoneura sp. & & & 8.5 \\
Stictochironomus sp. & & & 3.1 \\
Cryptochironomus sp. & & & \\
Eukieferiella spp. & & 2.9 & \\
Virgatanytarsus sp. & & 2.9 & \\
Micropsectra sp. & 6.2 & & \\
Cricotopus gr. bicinctus & 3.3 & & \\
Macropelopia & 3.0 & & \\
Phaenopsectra sp. & 3.0 & & \\
Brillia longifurca & 2.7 & & \\
Paratanytarsus sp. & 2.3 & & \\
Prodiamesa & 2.0 & & \\
\hline
\end{tabular}

${ }^{\text {a }}$ The taxonomic category mentioned as $O C P$ represents specimens of Cricotopus, Orthocladius and Paratrichocladius that are very difficult to distinguish based on morphological characteristics of larvae only.

Table A1 available online). Traits such as emergence period, life cycle duration and reproduction type were available for very few taxa present at the study sites $(<15 \%)$, reducing the initial list. Six traits cumulated $65 \%$ of the total variability of the FPCA performed on all traits: respiration type (tracheas), haemoglobin, tube construction, substrate relation, maximal body size and length of larval development, haemoglobin and respiration type were correlated (0.86), so only the respiration type was used in further analysis as it explains a higher variability in the multivariate distribution, showing a clear segregation between trait categories when compared with haemoglobin. Flight period and emergence season were only slightly correlated (about 0.38 ), although a correlation is expected as a product of a causal relationship, as flight period follows the emergence. Therefore, only emergence season was maintained; as it had information for more taxa and better explained data variability.

Among the 12 morphological traits, no relevant redundancy occurred between traits and therefore they were all kept for further analyses (Appendix Table A2 available online).

\section{Trait-by-sites arrays}

\section{Eltonian traits}

The first-two axes of the FCA extracted $47.9 \%$ of the total variability (64\% with FCA axis 3$)$. The betweenstream type FCA (BCA-FCA) performed on the Eltonian trait-by-site array showed low but significant differences among stream types $(17 \%$ of variance explained by stream type, simulated $P=0.008$; Fig. 3(A)). Decomposing the inertia of the BCA-FCA, Eltonian traits that contributed more (total of $85.0 \%$ ) to the differentiation of streamtypes in descending order were: diapause stages $(42.0 \%$, Fig. 3(B)), maximal body size (22.6\%, Fig. 3(C)), substrate relation $(10.9 \%$, Fig. $3(\mathrm{D}))$ and respiration type $(9.4 \%$, Fig. 3(E)). Within these traits, the relative proportion of some trait categories showed significant differences among stream types (Kruskal-Wallis and Dunn's test of multiple comparisons; Table 4(A)); a larger proportion of individuals with two or less larval stages exhibiting diapause occurred in PM streams (DIA2IN, Fig. 4(A)), whereas PL and TM had a significantly larger proportion of individuals with more than two larval stages exhibiting diapause (DIAMIN, Fig. 4(B)); the proportion of individuals with intermediate size (5-10 mm - SIZE3, Fig. 4(C)) was significantly lower in temporary streams (TM); and the proportion of burrowers (BURROW, Fig. 4(D)) was higher in temporary streams (TM).

\section{Morphological traits}

The first-two axes of the FCA were able to extract $60 \%$ of total variability of data. The between-stream type FCA analysis (BCA-FCA) performed on the morphological trait-by-site array showed significant differences between stream types $(20 \%$ of variance explained, simulated $P=0.008$; Fig. 5(A)). The traits that most contributed $(76.8 \%)$ to these differences decomposing the analysis inertia included: body setae (24.3\%, Fig. 5(B)), mentum (22.5\%, Fig. 5(C)), Lauterborn organs (16.6\%, Fig. 5(D)) and claws of the anterior parapod (13.5\%, Fig. 5(E)). The morphological trait categories within these most contributive traits that showed significantly different proportions among stream types (Kruskal-Wallis and Dunn's tests; Table 4(B)) were: pale/indistinct setae (SIND, Fig. 6(A)), higher in temporary streams (TM); long body setae (SETP, Fig. 6(B)), higher in PM streams; mentum holding a higher number of teeth, lower in PM streams (DTM, Fig 6(C)); indistinct Lauterborn organs (LOI, Fig. 6(D)), more frequent in TM temporary streams; finally PM streams were characterised by a significantly lower proportion of Chironomidae with simple claws (CASIM, Fig. 6(E)) and a significantly higher proportion of taxa with serrated claws (CASER, Fig. 6(F)).

\section{Discussion}

Odontomesa sp. and five other genera (Paracladius, Epoicocladius, Hydrobaenus, Paratendipes and Tribelos) 


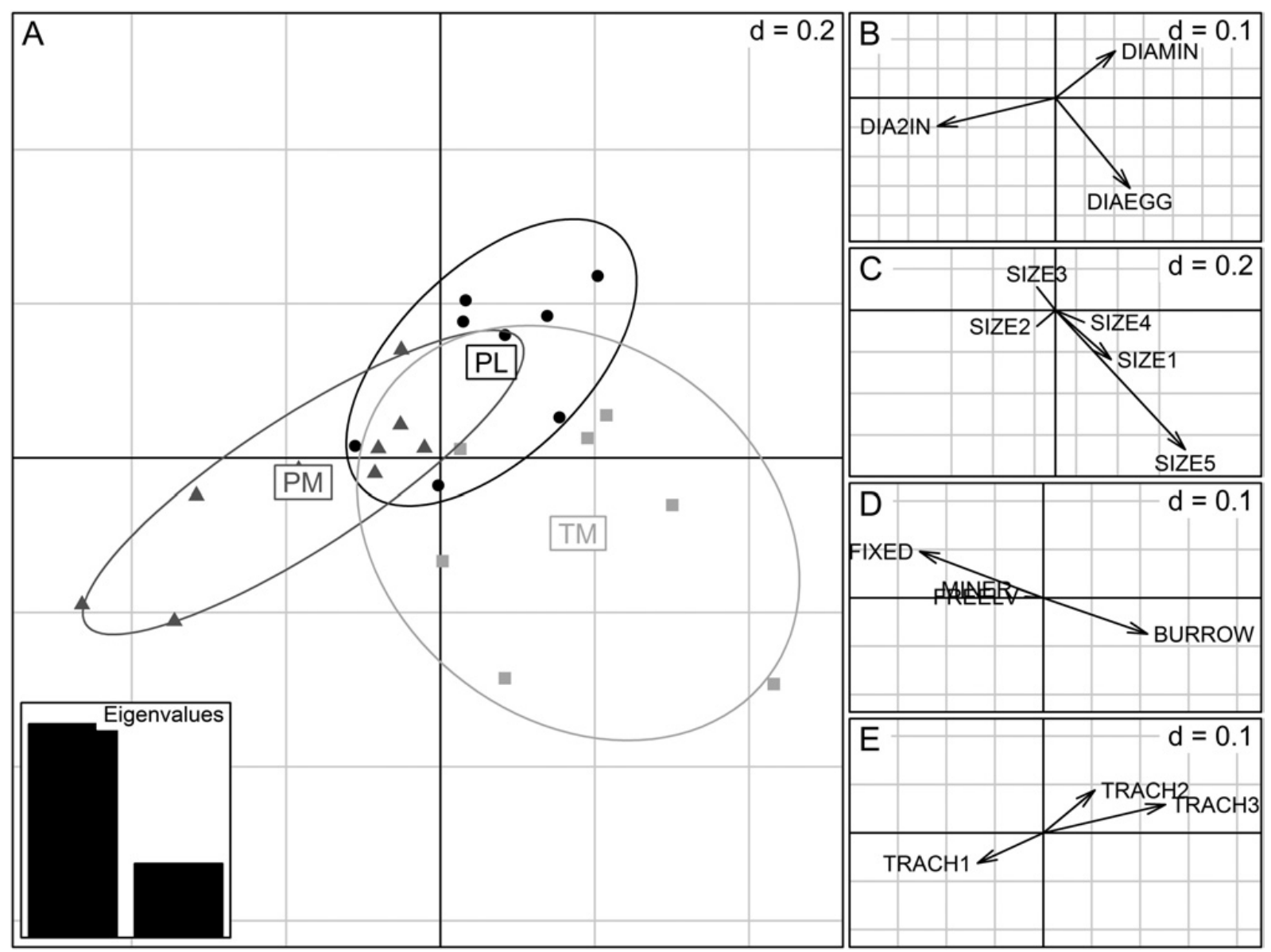

Fig. 3. First-two axes of the between-class analysis-fuzzy correspondence analyses (BCA-FCA, class: stream type) performed on the Eltonian traits-by-sites array. Each point represents a study site. Sites are grouped by stream type identified as: black circles permanent lowland streams, PL; dark grey squares - permanent medium-altitudes streams, PM; light grey squares- temporary southern streams, TM. Larger symbols represent the centre of ellipses.

Table 4. Kruskal-Wallis and Dunn's tests used for analysing differences between permanent and temporary stream types for traits and their categories (PL, permanent lowland northern streams; PM, medium-altitude northern streams; TM, temporary Mediterranean streams). (A) Eltonian traits. (B) Morphological traits.

\begin{tabular}{|c|c|c|c|c|}
\hline Trait category & Code & Chi-squared & $p$ & Dunn's test significance $(P<0.05)$ \\
\hline \multicolumn{5}{|l|}{ (A) Eltonian traits } \\
\hline \multirow[t]{2}{*}{ Diapause stages } & DIA2IN & 13.403 & 0.001 & $\mathrm{~N} 1 \neq \mathrm{L} ; \mathrm{N} 1 \neq \mathrm{S} 1$ \\
\hline & DIAMIN & 9.086 & 0.011 & $\mathrm{~N} 1 \neq \mathrm{L} ; \mathrm{N} 1 \neq \mathrm{S} 1$ \\
\hline Maximum body size & SIZE3 & 13.920 & 0.001 & $\mathrm{~S} 1 \neq \mathrm{L} ; \mathrm{S} 1 \neq \mathrm{N} 1$ \\
\hline Substrate relation & BURROW & 11.143 & 0.004 & $\mathrm{~S} 1 \neq \mathrm{L} ; \mathrm{S} 1 \neq \mathrm{N} 1$ \\
\hline \multicolumn{5}{|l|}{ (B) Morphological traits } \\
\hline \multirow[t]{2}{*}{ Body setae } & SIND & 12.045 & 0.002 & $\mathrm{~S} 1 \neq \mathrm{L} ; \mathrm{S} 1 \neq \mathrm{N} 1$ \\
\hline & SETP & 7.279 & 0.026 & $\mathrm{~N} 1 \neq \mathrm{L}$ \\
\hline Mentum & DTM & 12.123 & 0.002 & $\mathrm{~N} 1 \neq \mathrm{L} ; \mathrm{N} 1 \neq \mathrm{S} 1$ \\
\hline Lauterborn organs & LOI & 7.493 & 0.024 & $\mathrm{~S} 1 \neq \mathrm{L} ; \mathrm{S} 1 \neq \mathrm{N} 1$ \\
\hline \multirow[t]{2}{*}{ Claws of anterior parapods } & CASIM & 11.468 & 0.003 & $\mathrm{~N} 1 \neq \mathrm{L} ; \mathrm{N} 1 \neq \mathrm{S} 1$ \\
\hline & CASER & 7.495 & 0.024 & $\mathrm{~N} 1 \neq \mathrm{L} ; \mathrm{N} 1 \neq \mathrm{S} 1$ \\
\hline
\end{tabular}

found in our samples were not described for Portugal by the Fauna Europaea (Saether and Spies, 2013). Epoicocladius is a widespread European parasite of nymphs of Ephemera (Moller Pillot, 2013), which is a common Ephemeroptera in northern Portuguese rivers.
Paratendipes sp. was previously found in montane streams of Serra-da-Estrela, Portugal (Rieradevall et al., 2007) and in southern Mediterranean streams in Spain (Baranov, 2014). Here, however, it was also collected in permanent lowland streams suggesting that they might have wider 

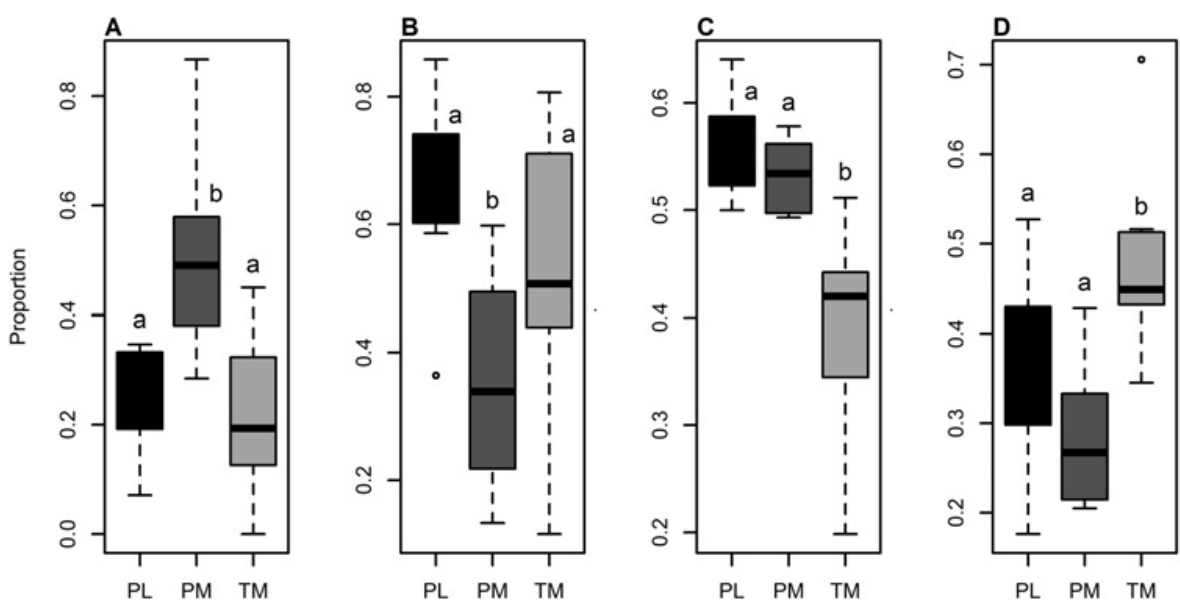

Fig. 4. Eltonian trait categories that contribute to differences between stream types (PM, permanent northern medium-altitude streams; PL, permanent lowland streams; TM, southern temporary streams): (A) $\leq 2$ larval stages with diapause, DIA2IN; (B) > 2 larval stages with diapause, DIAMIN; (C) intermediate size 5-10 mm, SIZE3; (D) burrowers, BURROW; Dunn's test results are shown as "a" and "b" associated with each box. Stream types not sharing the same letter are significantly different.

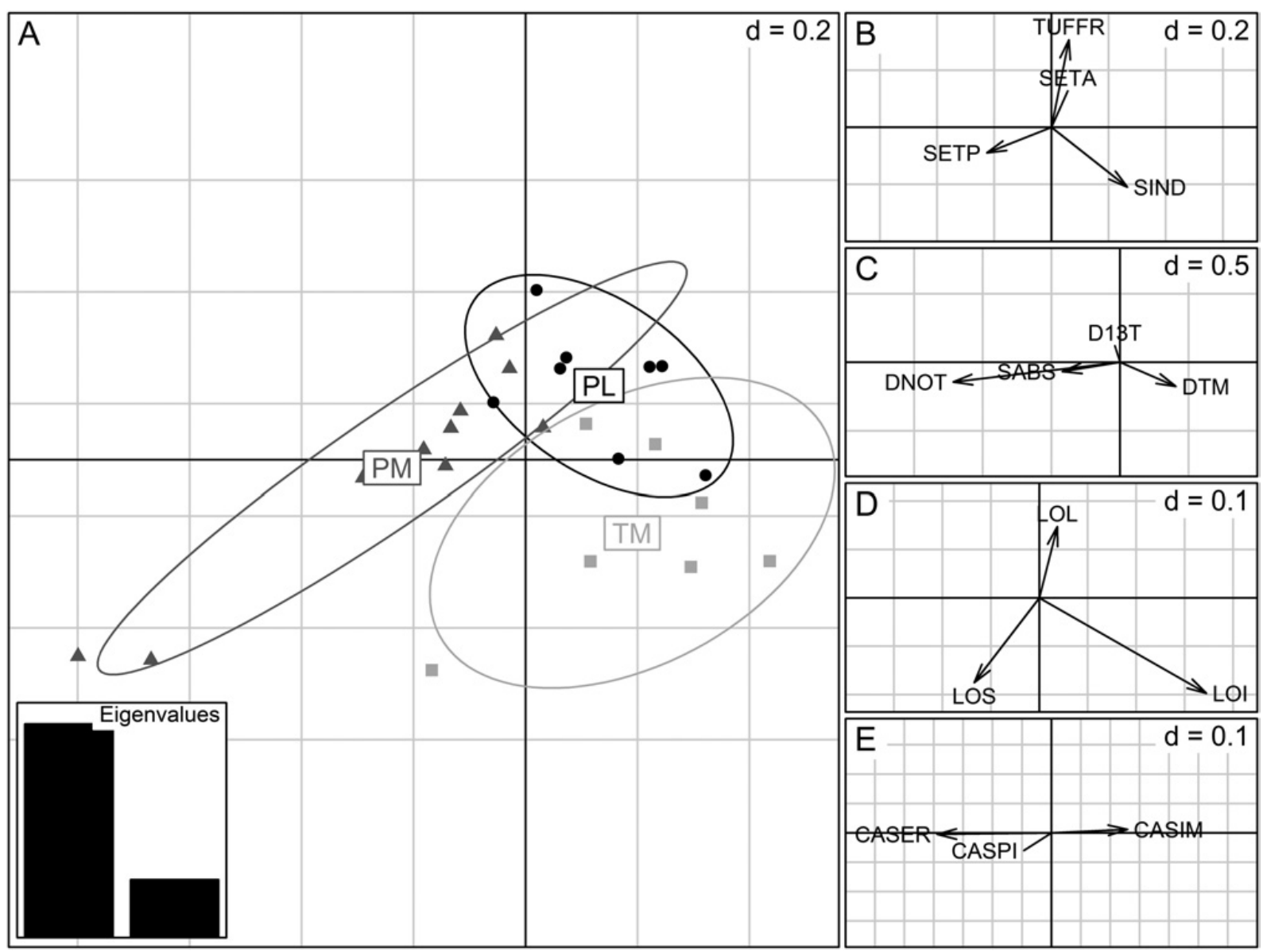

Fig. 5. First-two axes of the between-class analysis-fuzzy correspondence analyses (BCA-FCA, class: stream type) performed on the morphological traits-by-sites array. Each point represents a study site. Sites are grouped by stream type identified as: black circles permanent lowland streams, PL; dark grey squares - permanent medium-altitudes streams, PM; light grey squares - temporary southern streams, TM. Larger symbols represent the centre of ellipses. 

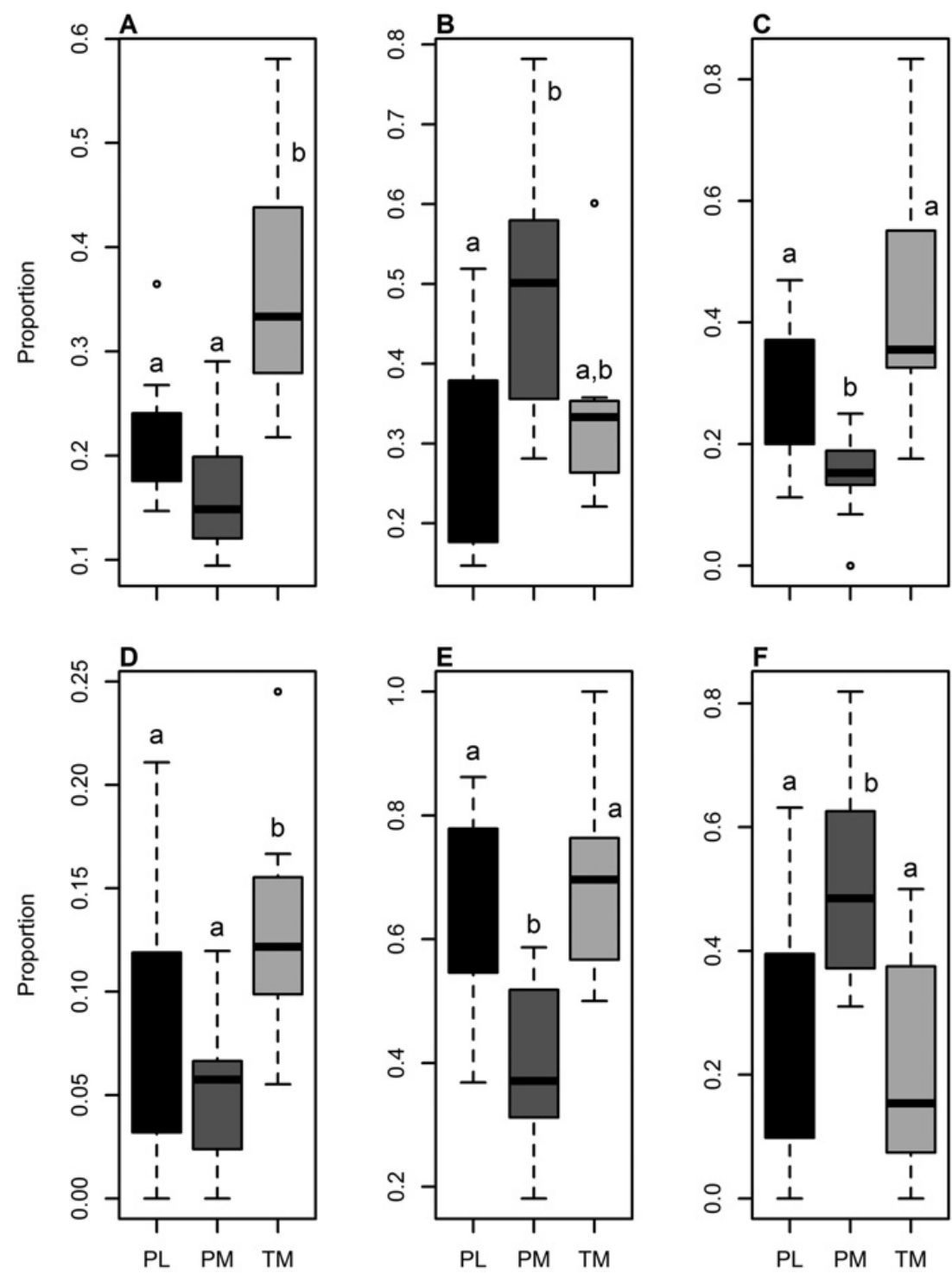

Fig. 6. Morphological trait categories that contribute to differences among stream types (PM, permanent northern medium-altitude streams; PL, permanent lowland streams; TM, temporary southern streams): (A) body setae pale/indistinct, SIND; (B) long body setae, SETP; (C) mentum with more than 13 teeth, DTM; (D) Lauterborn organs indistinct, LOI; (E) presence of premandible brush, PMBP; (F) simple claws of anterior parapod, CASIM; $(\mathrm{G})$ claws of anterior parapod serrated, CASER. Dunn's test results are shown as letters "a" and "b" associated with each box. Stream types not sharing the same letter are significantly different.

ecological ranges. The Hydrobaenus sp. has been considered a typical member of temporary stream communities, building cocoons to face desiccation (Moller Pillot, 2013) and we found it only in temporary streams. However, there are also records of its presence in Portuguese montane rivers (Rieradevall et al., 2007). Tribelos and Paratendipes were exclusively found in temporary rivers and previous studies have indicated their preference for stagnant waters (Moller Pillot, 2009, 2013), potentially occurring in these rivers during summer. As far as we know, the present study is the first that reveals the presence of Odontomesa, Paracladius, Epoicocladius and Tribelos in Portugal (but these taxa were recorded in Spain by Saether and Spies, 2013) showing the lack of knowledge on Portuguese Chironomids.
Here we showed that within macroinvertebrates, the structure and abundance of Chironomidae alone reflect the natural differences of physical and chemical conditions between permanent and temporary streams and also between two types of permanent streams (lowland versus medium altitude streams). Differences in Chironomidae composition between stream types were also found by Puntí et al. (2007) in the Mediterranean streams from the north-east of Spain. Identifying Chironomidae at subfamily level did, however, not allow for full segregation of stream types (no differences between different types of permanent streams), showing the importance of a higher taxonomic resolution in ecological studies (Lenat and Resh, 2001) and questioning previous recommendations for the elimination of Chironomidae from bioassessment 
protocols or their use at the family or subfamily level as a result of difficulties in the identification of Chironomids down to the genus and species level (e.g., Rabeni and Wang, 2001; Móra et al., 2008).

Water temperature, current velocity, substrate type and food availability are critical factors in the distribution of macroinvertebrates in general and Chironomidae assemblage in particular (Prat et al., 1983; Lindegaard and Brodersen, 1995; Rossaro et al., 2006; Lencioni et al., 2007). We also detected changes in Chironomidae composition between the two permanent stream types, which are probably related to differences in granulometry and water temperature along the longitudinal gradient and altitudinal gradient. The major differences in Chironomidae communities nonetheless reflected the latitudinal and climatic gradient: south temporary Mediterranean streams (TM) from northern permanent streams with an Atlantic temperate climate (PL and PM). These differences challenge the notion of Chironomidae as environmental generalist taxa, the practical result of restraining their use at coarser taxonomic levels, as has often been argued (King and Richardson, 2002) but still unable to counter the constant neglect of the family.

Regarding the most representative taxa of each stream type, our study confirmed some information from previous studies in the Iberian Peninsula, but also brought additional knowledge on genus distribution and tolerances. In the permanent medium altitude streams, Conchapelopia sp. (Tanypodinae) had a high contribution to the similarity among streams. This is consistent with its association with fast-flowing waters or well-oxygenated lake habitats (Vallenduuk and Moller Pillot, 2007). Virgatanytarsus sp. (Chironominae, Tanytarsini) was also representative of these streams, which is in accordance with studies by Puntí et al. (2009) that refer to an altitude optimum below $500 \mathrm{~m}$. In both permanent stream types (PL and PM), the genera Parametriocnemus sp. (Orthocladiinae) and Polypedilum sp. (Chironomini) were relatively well represented. This is consistent with other studies that showed that these genera are present not only at higher but also at lower altitudes (Rossaro et al., 2006; Moller Pillot, 2013). The prodiamesinae subfamily was found only in permanent lowland rivers (PL), represented by two genera: Prodiamesa sp. and Odontomesa sp. In both cases, previous references (Moller Pillot, 2013) justify this distribution: Prodiamesa is well adapted to rivers with deposition of organic matter; while Odontomesa is a freeliving passive filter-feeder that drives water in and out by peristaltic movements, and feeds mainly on unicellular algae retained by specialised mouthparts, requiring low current velocities and sandy bottoms.

Temporary Mediterranean rivers are characterised by marked seasonality in flow regime, alternating large floods and severe droughts (Gasith and Resh, 1999; Puntí et al., 2007). In our study, the Diamesinae (Potthastia gr. gaedii) dominated temporary stream assemblages. This family is common in cold fast-flowing waters, but Potthastia gaedii has also been reported in mid and lowland river sections with stony bottoms (Puntí et al., 2007; Moller Pillot,
2013). Accordingly, this genus occurs in our permanent rivers (both at medium and low altitude) but surprisingly it was only considered a representative species in temporary streams. The high number of individuals found in our temporary streams must be related to the availability of microhabitats required by $P$. gaedii bottom dwellers, as our temporary streams are characterised by great sediment heterogeneity. Corynoneura sp. (Orthocladiinae) was considered a representative species of our temporary Mediterranean rivers but not of the remaining types. However, within this genus, the congeneric species have different ecological preferences: some Corynoneura species are specifically associated with headwaters, mid-high altitudes, siliceous substrates and low temperature, while C. coronata for example occurred in carbonate waters with higher temperatures (Puntí et al., 2009). This is an example where a lower level of taxonomic resolution (species) would contribute to the discrimination of types.

Eltonian and morphological Chironomidae traits disclosed differences among stream types. This was expected, as abiotic characteristics (e.g., photoperiod and temperature) that differ among stream types, are known to influence the selected traits, such as larval growth, diapause, emergence of adults, duration of life cycles and emergence period. However, not all of these traits have shown significant differences among these natural stream types. Burrowing should increase resistance against droughts and flood events (Bonada et al., 2007b). Small body size is generally associated with fast reproduction and development, conferring resilience to disturbance (e.g., Corynoneura sp.). Simultaneously, large body sizes are advantageous in stagnant pools during the low flow period (Bonada et al., 2007b). Temporary streams were segregated by their significantly higher proportion of burrowers and lower proportion of intermediate sizes. Diapause, especially overwintering diapause was expected to occur in more Chironomidae stages (DIAMIN) in colder streams to face the lower temperature challenges, but this trait category was much higher in PL and TM, characterised by higher temperatures throughout the year, probably reflecting other types of diapause in a larger number of larval stages, to avoid desiccation. The condition of dormancy and torpor in Chironomidae is controversial: Armitage et al. (1995), Vallenduuk and Moller Pillot (2007) and Moller Pillot (2009, 2013) mentioned its occurrence, while Andersen et al. (2013) did not consider it. Our results suggest that diapause may be used by Chironomidae to face cold temperatures but perhaps also high temperatures to avoid desiccation (aestivation). More Chironomidae autoecological studies are needed to clarify patterns of diapause and emergence and link these patterns to temperature (Goddeeris, 1990) Information about traits related to resistance, but also resilience by dispersal and colonisation are also still scarce for many Diptera, including Chironomidae, and are crucial since Chironomidae are recognised as the first colonisers after natural disturbances caused by floods and droughts (Delettre, 1988; Delettre and Morvan, 2000; Marziali et al., 2010). 
In this study, we investigated the ecological relevance of Chironomidae morphological traits, which are absent in general macroinvertebrate trait databases. Studies on other groups of organisms have related the occurrence of taxa with specific morphological traits to their habitats. For example, Makkonen et al. (2011) found that largersized Collembola with a higher number of oecelli and body pigmentation were favoured by dryness, showing their resistance to desiccation. The importance of abdominal setae and body size of two Chironomidae species (Cricotopus bicinctus and C. sylvestris) in predator avoidance was previously studied by Hershey and Dodson (1987), exposing the link between these morphological traits and a particular type of external factor. The great advantage of such morphological traits is that they do not require the identification of individuals, the existence of previous taxonomic studies, and taxonomic keys on local fauna. These traits could thus enable ecological interpretations free of taxonomic errors. On the other hand, their use may be limited, since they are restricted to some taxonomic groups because morphological traits are not shared by all invertebrate groups. To enlarge their use to more families would require the identification of analogous structures that would play the same key role in the environment.

In fact, some Chironomidae morphological traits reflected ecological differences in the three stream types. Chironomidae with long body setae were more frequent in northern permanent streams, distinguishing them from the lowland streams, whereas short setae were more frequent in temporary streams. In northern streams, setae allow organisms to anchor to coarse substrate, whereas in temporary streams small setae allow burrowing. Chironomidae without teeth on the mentum were also more frequent in northern permanent streams. The mentum architecture together with other structures of the head capsule reflect evolutionary adjustments of feeding habits but also other activities such as silk production and construction of tubes or cases (Armitage et al., 1995). Here, the lower sclerotisation of the mentum (less teeth) may facilitate swallowing various prey, whereas numerous teeth may facilitate particle entrapment and substrate surface scraping, and thus opportunistic omnivores. Taxa with inconspicuous Lauterborn organs were more frequent in temporary streams, distinguishing them from the other two types. Lauterborn organs are sensory structures located in the second antennal segment or at its apex. These organs allow Chironomidae to actively explore their habitat, especially in foraging activities. However, at the same time, these thin-walled sensors are particularly vulnerable to the surroundings, and thus the reduction of these organs is known to occur in terrestrial Chironomidae (Cranston, 1995). So, the possible vulnerability of Lauterborn organs may be a reason for their reduction in highly variable temporary streams in the Mediterranean climate, but little information is available on this subject. Claws and length of the Chironomidae posterior parapods have an important function in fast current and unstable substrate for stabilising
Chironomidae bodies (Lencioni et al., 2007). In fact, Chironomidae with serrated claws of the anterior parapod were more frequent in permanent northern streams where current velocities are higher.

This study highlights the importance of the use of at least the genus level in ecological studies and to define robust reference conditions for bioassessment. The two sets of traits, i.e., the Eltonian traits derived from a fuzzy coding trait database for European Chironomidae genera (potential traits), and the morphological traits directly observed in the organisms (fundamental traits), were found to be useful in the discrimination between stream types, especially between permanent and temporary streams. Both sets of traits gather some intraspecific variability inside each Chironomidae genus: one by using a fuzzy coding system that establishes different affinity degrees to different trait categories in European genera; another by relying on the observation of sampled specimens conceptually moving towards the description of the "realised trait" profiles of taxa (accepted as a part of their "realised niche"). The intraspecific trait variability and trait plasticity of Chironomidae species as a response to a wide range of environmental conditions may be one of the great adaptive advantages of this insect family and one of the reasons they are distributed in diverse freshwater environments. Chironomidae morphological traits could be an interesting tool for ecological studies, reflecting differences among stream types and avoiding the use of potential traits derived from general trait databases. The use of traits as morphological characteristics related to functions that Chironomidae perform in their habitat can avoid their laborious identification, which depends on the observation of numerous minute structures, relying instead on the observation of fewer morphological characteristics that in some cases do not even require a microscope, opening alternatives to the need for extensive taxomomic expertise. However, poor knowledge of the relationship between morphological characteristics (e.g., antennal blade, procercus setae) and their ecological functions highlights the need for further research to identify relevant traits and the definition of trait categories with ecological meaning that are easier to observe and measure. Finally, future studies should examine the relevance of Eltonian and morphological traits in distinguishing different impairment levels.

\section{Supplementary material}

The supplementary material for this article can be found at http://dx.doi.org/10.1051/limn/2017004.

Acknowledgements. This study was supported by the Fundação para a Ciência e Tecnologia (FCT), through the strategic project UID/MAR/04292/2013 granted to MARE, the grant awarded to Sónia Serra (SFRH/BD/80188/2011). It was also made possible through co-tutelage between the University of Coimbra and the University of Lyon 1; cooperation between the MARE UC and the LEHNA - Laboratoire d'Ecologie des Hydrosystèmes 
Naturels et Anthropisés, University of Lyon, France. The research partly benefited from the European Union's Seventh Framework Programme, Grant Agreement No. 603629-ENV2013-6.2.1-Globaqua. The identification was supported by Narcís Prat from the Research Group F.E.M. (Freshwater Ecology and Management), from the Department of Ecology at the University of Barcelona, Spain.

\section{References}

Allan J.D., 1995. Stream Ecology. Structure and Functions of Running Waters, Kluwer Academic Publishers, Dordrecht, Netherlands, 388 p.

Andersen T., Cranston P.S. and Epler J.H. (eds.), 2013. Chironomidae of the Holartic Region. Keys and Diagnoses - Larvae, Insect Systematics and Evolution, Supplement 66, Lund, Sweden, 573 p.

Armitage P., Cranston P.S. and Pinder L.C.V. (eds.), 1995. The Chironomidae. The Biology and Ecology of Non-Biting Midges, Chapman \& Hall, London, 572 p.

Astor T., Strengbom J., Berg M.P., Lenoir L., Marteinsdóttir B. and Bengtsson J., 2014. Underdispersion and overdispersion of traits in terrestrial snail communities on islands. Ecol. Evol., 4, 2090-2102.

Bady P., Dolédec S., Fesl C., Gayraud S., Bacchi M. and Schöll F., 2005. Use of invertebrate traits for the biomonitoring of European large rivers: the effects of sampling effort on genus richness and functional diversity. Freshwat. Biol., 50, 159-173.

Baranov V.A., 2014. Additions to the inventory of the Portuguese chironomids (Diptera: Chironomidae, based on material from Vaiamonte parish. Dipteron, 30, $2-7$.

Bonada N., Rieradevall M. and Prat N., 2007a. Macroinvertebrate community structure and biological traits related to flow permanence in a Mediterranean river network. Hydrobiologia, 589, 91-106.

Bonada N., Dolédec S. and Statzner B., 2007b. Taxonomic and biological trait differences of stream macroinvertebrate communities between Mediterranean and temperate regions: implications for future climatic scenarios. Glob. Change Biol., 13, 1658-1671.

Brown L.E., Hannah D.M. and Milner A.M., 2007. Vulnerability of alpine stream biodiversity to shrinking glaciers and snowpacks. Glob. Change Biol., 13, 958-966.

Calle-Martínez D. and Casas J.J., 2006. Chironomid species, stream classification, and water-quality assessment: the case of 2 Iberian Mediterranean mountain regions. J. N. Am. Benthol. Soc., 25, 465-477.

Chessel D., Dufour A.B. and Thioulouse J., 2004. The ade4 package - I: one-table methods. R. News, 4, 5-10.

Chevenet F., Dolédec S. and Chessel D., 1994. A fuzzy coding approach for the analysis of long-term ecological data. Freshwat. Biol., 31, 295-309.

Coffman W.P. and Ferrington L.C., 1996. Chironomidae. In: Merritt R.W. and Cummins K.W. (eds.), An Introduction to the Aquatic Insects of North America (3rd edn), Kendall/ Hunt Publishing Company, Dubuque, 635-754.

Cranston P.S., 1982. A Key to the Larvae of the British Orthocladiinae (Chironomidae), Freshwater Biological Associations Scientific Publication no 45, Ambleside, 152 p.
Cranston P.S., 1995. Morphology. In: Armitage P., Cranston P.S. and Pinder L.C.V. (eds.), The Chironomidae. The Biology and Ecology of Non-biting Midges, Chapman \& Hall, London, 11-30.

Delettre Y.R., 1988. Chironomid wing length, dispersal ability and habitat predictability. Holarct. Ecol., 11, 166-170.

Delettre Y.R. and Morvan N., 2000. Dispersal of adult aquatic Chironomidae (Diptera) in agricultural landscapes. Freshwat. Biol., 44, 399-411.

Devin S., Beisel J.-N., Usseglio-Polatera P. and Moreteau J.-C., 2005. Changes in functional biodiversity in an invaded freshwater ecosystem: the Moselle River. Hydrobiologia, $542,113-120$.

Dolédec S. and Chessel D., 1987. Rythmes saisonniers et composantes stationnelles en milieu aquatique. I. Description d'un plan d'observation complet par projection de variables. Acta Oecol. - Oec. Gen., 8, 403-426.

Dolédec S. and Statzner B., 2010. Responses of freshwater biota to human disturbances: contribution of J-NABS to developments in ecological integrity assessments. J. N. Am. Benthol. Soc., 29, 286-311.

Dray S. and Dufour A.B., 2007. The ade4 package: implementing the duality diagram for ecologists. J. Stat. Softw., 22, $1-20$.

Dray S., Dufour A.B. and Chessel D., 2007. The ade4 package - II: two-table and K-table methods. R. News, 7, 47-52.

European Commission, 2000. Directive 2000/60/EC of the European Parliament and of the Council of 23 October 2000 establishing a framework for community action in the field of water policy. Off. J. Eur. Comm., L327, $1-73$.

Feio M.J. and Dolédec S., 2012. Integration of invertebrate traits into predictive models for indirect assessment of stream functional integrity: a case study in Portugal. Ecol. Indic., 15, 236-247.

Feio M.J., Aguiar F.C., Almeida S.F.P., Ferreira J., Ferreira M.T., Elias C., Serra S.R., Buffagni A., Cambra J., Chauvin C., Delmas F., Dörflinger G., Erba S., Flor N., Ferréol M., Germ M., Mancini L., Manolaki P., Marcheggiani S., Minciardi M.R., Munné A., Papastergiadou E., Prat N., Puccinelli C., Rosebery J., Sabater S., Ciadamidaro S., Tornés E., Tziortzis I., Urbanic G., and Vieira C., 2014. Least disturbed conditions for European Mediterranean rivers. Sci. Total Environ., 476-477, 745-756.

Franquet E., 1996. Occupation d'un espace fluvial par les Diptères Chironomidés à l'aval du Rhône : répartition des espèces selon la nature du substrat et les conditions de débit. $\mathrm{PhD}$ thesis, Université Lyon 1, Villeurbanne.

Gasith A. and Resh V.H., 1999. Streams in Mediterranean climate regions: abiotic influences and biotic responses to predictable seasonal events. Annu. Rev. Ecol. Evol. Syst., 30, 51-81.

Goddeeris B.R., 1990. Life cycle characteristics in Tanytarsus sylvaticus (van der Wulp, 1859) (Chironomidae, Diptera). Ann. Limnol. - Int. J. Lim., 26, 51-64.

Greffard M.-H., Saulnier-Talbot É. and Gregory-Eaves I., 2011. A comparative analysis of fine versus coarse taxonomic resolution in benthic chironomid community analyses. Ecol. Indic., 11, 1541-1551.

Harrison S.S.C., Pretty J.L., Shepherd D., Hildrew A.G., Smith C. and Hey R.D., 2004. The effect of instream 
rehabilitation structures on macroinvertebrates in lowland rivers. J. Appl. Ecol., 41, 1140-1154.

Hawkins C.P. and Norris R.H., 2000. Effects of taxonomic resolution and use of subsets of fauna on the performance of RIVPACS-type models. In: Wright J.F., Sutcliffe D.W. and Furse M.T. (eds.), Assessing the Biological Quality of Freshwaters RIVPACS and Other Techniques, Freshwater Biological Association, Ambleside, Cumbria, 217-228.

Heino J., Mykrä H., Kotanen J. and Muotka T., 2007. Ecological filters and variability in stream macroinvertebrate communities: do taxonomic and functional structure follow the same path? Ecography, 30, 217-230.

Hershey A.E. and Dodson S.I., 1987. Predator avoidance by Cricotopus: cyclomorphosis and the importance of being big and hairy. Ecology, 68, 913-920.

INAG, 2008. Manual para a avaliação biológica da qualidade da água em sistemas fluviais segundo a directiva quadro da água, Protocolo de amostragem e análise para os macroinvertebrados bentónicos, Ministério do Ambiente, do Ordenamento do Território e do Desenvolvimento Regional, Instituto da Água, I.P., Portugal, 61 p.

Karr J., 1991. Biological integrity: a long-neglected aspect of water resource management. Ecol. Appl., 1, 66-84.

King R.S. and Richardson C.J., 2002. Evaluating subsampling approaches and macroinvertebrate taxonomic resolution for wetland bioassessment. J. N. Am. Benthol. Soc., 21, 150-171.

Lenat D.R. and Resh V.H., 2001. Taxonomy and stream ecology - the benefits of genus- and species-level identifications. J. N. Am. Benthol. Soc., 20, 287-298.

Lencioni V., Marziali L. and Rossaro B., 2007. I Ditteri Chironomidi. Morfologia, tassonomia, ecologia, fisiologia e zoogeografia, Museo Tridentino di Scienze Naturali, Trento. Quaderni del Museu Tridentino di Scienze Naturali, $1,172 \mathrm{p}$.

Lencioni V., Marziali L. and Rossaro B., 2012. Chironomids as bioindicators of environmental quality in mountain springs. Freshwat. Sci., 31, 525-541.

Lencioni V., Bernabò P., Cesari M., Rebecchi L. and Cesari M., 2013. Thermal stress induces HSP70 proteins synthesis in larvae of the cold stream non-biting midge Diamesa cinerella Meigen. Arch. Insect. Biochem. Physiol., 83, 1-14.

Lindegaard C.B. and Brodersen K.P., 1995. Distribution of Chironomidae (Diptera) in the River Continuum. In: Cranston P. (ed.), Chironomids: from Genes to Ecosystems, CSIRO Publications, Melbourne, 257-271.

Makkonen M., Berg M.P., van Hal J.R., Callaghan T.V., Press M.C. and Aerts R., 2011. Traits explain the responses of a sub-arctic Collembola community to climate manipulation. Soil Biol. Biochem., 43, 377-384.

Marziali L., Giordano A., Cazzola M., Erba S., Toppi E., Buffagni A. and Rossaro B., 2010. Responses of Chironomid larvae (Insecta, Diptera) to ecological quality in Mediterranean river mesohabitats (South Italy). River Res. Applic., 26, 1036-1051.

Moller Pillot H.K.M., 2009. Chironomidae Larvae - Biology and Ecology of the Chironomini, KNNV Publishing, The Netherlands, $270 \mathrm{p}$.

Moller Pillot H.K.M., 2013. Chironomidae Larvae - Biology and Ecology of the Aquatic Orthocladinae, KNNV Publishing, The Netherlands, $312 \mathrm{p}$.
Móra A., Csépes E., Tóth M. and Dévai G., 2008. Spatiotemporal variations of macroinvertebrate community in the Tisza River (NE Hungary). Acta Zool. Acad. Sci. Hung., 54, 181-190.

Poff N.L., 1996. A hydrogeography of unregulated streams in the United States and an examination of scaledependence in some hydrological descriptors. Freshwat. Biol., 36, 71-91.

Portuguese Environmental Agency, 2007. Sistema Nacional de Informação de Ambiente. Available online at: http://sniamb.apambiente.pt/Home/Default.htm. Last accessed 12 July 2016.

Prat N. and Rieradevall M., 2014. Guia para el reconocimiento de las larvas de Chironomidae (DIPTERA) de los ríos mediterráneos. Version 1. Available online at: http://hdl.handle.net/2445/60584. Last accessed 12 July 2016.

Prat N., Puig M.A., González G. and Millet X., 1983. Chironomid longitudinal distribution and macroinvertebrate diversity along the Llobregat River (NE Spain). Mem. Am. Entomol. Soc., 34, 267-278.

Puntí T., Rieradevall M. and Prat N., 2007. Chironomidae assemblages in reference condition Mediterranean streams: environmental factors, seasonal variability and ecotypes. Fundam. Appl. Limnol., 170, 149-165.

Puntí T., Rieradevall M. and Prat N., 2009. Environmental factors, spatial variation and specific requirements of Chironomidae in Mediterranean reference streams. J. N. Am. Benthol. Soc., 28, 247-265.

R Core Team, 2015. R: a Language and Environment for Statistical Computing, $\mathrm{R}$ Foundation for Statistical Computing, Vienna, Austria. Available online at: http:// www.r-project.org/.

Rabeni C.F. and Wang N., 2001. Bioassessment of streams using macroinvertebrates: are the Chironomidae necessary? Environ. Monit. Assess., 71, 177-185.

Reynoldson T.B., Norris R.H., Resh V.H., Day K.E. and Rosenberg D.M., 1997. The reference condition: a comparison of multimetric and multivariate approaches to assess water-quality impairment using benthic macroinvertebrates. J. N. Am. Benthol. Soc., 16, 833-852.

Rieradevall M., Chaves M.L. and Prat N., 2007. High altitude Chironomidae (Diptera) of Serra da Estrela (Portugal): additions to the Portuguese and Iberian Peninsula Fauna. Graellsia, 63, 273-278.

Robert P. and Escoufier Y., 1976. A unifying tool for linear multivariate statistical methods: the RV-coefficient. J. R. Stat. Soc. C-Appl., 25, 257-265.

Rosenberg D.M. and Resh V.H., 1993. Freshwater Biomonitoring and Benthic Macroinvertebrates, Chapman \& Hall, New York, 488 p.

Rossaro B., Lencioni V., Boggero A. and Marziali L., 2006. Chironomids from Southern Alpine running waters: ecology, biogeography. Hydrobiologia, 562, 231-246.

Saether O.A. and Spies M., 2013. Fauna Europaea: Chironomidae. In: Beuk P. and Pape T. (eds.), Fauna Europaea: Diptera, Fauna Europaea Version 2.6.2. Available online at: http://www.faunaeur.org/. Last accessed 12 July 2016.

Serra S.R.Q., Cobo F., Graça M.A.S., Dolédec S. and Feio M.J.F., 2016. Synthesising the trait information of European Chironomidae (Insecta: Diptera): toward a new database. Ecol. Indic., 61, 282-292. 
Statzner B., Bady P., Dolédec S. and Schöll F., 2005. Invertebrate traits for the biomonitoring of large European rivers: an initial assessment of trait patterns in least impacted river reaches. Freshwat. Biol., 50, 2136-2161.

Statzner B., Bonada M. and Dolédec S., 2008. Biological attributes discriminating invasive from native European stream macroinvertebrates. Biol. Invasions, 10, 517-530.

Stoddard J., Larsen D.P., Hawkins C.P., Johnson R.K. and Norris R.H., 2006. Setting expectations for the ecological condition of streams: the concept of reference condition. Ecol. Appl., 16, 1267-1276.

Ter Braak C.F.J., 1988. Partial canonical correspondence analysis. In: Bock H.H. (ed.), Classification and Related Methods of Data Analysis, North-Holland, Amsterdam, 551-558.
Tokeshi M., 1995. Life cycles and population dynamics. In: Armitage P., Cranston P.S. and Pinder L.C.V. (eds.), The Chironomidae. The Biology and Ecology of Non-biting Midges, Chapman \& Hall, London, 225-268.

Usseglio-Polatera P., Bournaud M., Richoux P. and Tachet H., 2000. Biomonitoring through biological traits of benthic macroinvertebrates: how to use species trait data bases? Hydrobiologia, 422/423, 173-181.

Vallenduuk H.J. and Moller Pillot H.K.M., 2007. Chironomidae Larvae - General Ecology and Tanypodinae, KNNV Publishing, The Netherlands, $144 \mathrm{p}$.

Wymer D.A. and Cook S.B., 2003. Effects of Chironomidae (Diptera) taxonomic resolution on multivariate analyses of aquatic insect communities. J. Freshwat. Ecol., 18, 179-186. 